\title{
Effect of an HIV/AIDS tailored health education program in Western China: An intervention study
}

\author{
Wan-Xia Yao ${ }^{1}$, Ming Yao ${ }^{2}$, Xiao-Ping Liu ${ }^{* 1}$, Hua Fang ${ }^{3}$, Shu-Min Zhao ${ }^{1}$, Rui-Jun Wang ${ }^{1}$, Cong Yao ${ }^{4}$, Di-Mao Wang ${ }^{3}$ \\ ${ }^{1}$ The First Affiliated Hospital of Xi'an Jiaotong University, Shaanxi Province, China \\ ${ }^{2}$ The Fifth Hospital of Xi'an City, Shaanxi Province, China \\ ${ }^{3}$ The Medical college of Xi'an Jiaotong University, Shaanxi Province, China \\ ${ }^{4}$ The Second Affiliated Hospital of Xi'an Jiaotong University, Shaanxi Province, China
}

Received: March 8, 2015

DOI: $10.5430 /$ jnep.v5n10p16
Accepted: June 7, $2015 \quad$ Online Published: July 7, 2015

URL: http://dx.doi.org/10.5430/jnep.v5n10p16

\begin{abstract}
This study is to explore the effect of a tailored health education program (THEP) to enhance knowledge of human immunodeficiency virus infection/acquired immunodeficiency syndrome (HIV/AIDS) among migrant construction workers (MCWs) in Western China. The THEP was given to $434 \mathrm{MCWs}$ working at three construction sites in Xi'an city, Shaanxi province from December 2011 to May 2012. The MCWs were invited to complete identical baseline and follow-up questionnaire surveys. Before the THEP was conducted, awareness of HIV/AIDS was poor among these MCWs. Knowledge and attitudes among the MCWs significantly improved after implementation of the program. In conclusions: THEPs that educate people regarding HIV/AIDS are urgently needed in China, especially for itinerant workers. THEPs can significantly improve knowledge and attitudes regarding HIV/AIDS.
\end{abstract}

Key Words: Health education, HIV/AIDS, Migrant construction workers

\section{INTRODUCTION}

According to the World Health Organization (WHO) Global HIV/AIDS Progress Report 2011, ${ }^{[1]}$ approximately 34.0 million people suffer from human immunodeficiency virus (HIV) infection. ${ }^{[2]}$ The increasing spread of HIV infection and acquired immunodeficiency syndrome (HIV/AIDS) is still an international public health problem, especially in developing coutries. As the biggest developing country, the prevalence of HIV in China was 780,000 at the end of 2011. ${ }^{[3]}$ On the other hand, the mainland China in the past few decades has undergone rapid economic growth and urbanization, ${ }^{[4]}$ during this time, migrant workers have had an increasingly important role in China's economic development and construction. These workers are mostly ex-farmers who leave the countryside for work in cities, while their spouses remain in their hometown. The majority work in the construction industry, moving from place to place, and they are at high-risk of contracting and spreading HIV/AIDS. ${ }^{[5]}$ Growing concern regarding the increased spread of HIV/AIDS in China has focused attention on its large migratory population. ${ }^{[6,7]}$ Similarly, in Africa and other countries, studies have shown that migratory populations contribute to the epidemic of HIV infections, ${ }^{[8]}$ and ruralto-urban economic migration is a key driver of increased HIV infections. ${ }^{[5]}$ In China, a number of HIV prevention programs have been implemented, but most studies have

\footnotetext{
*Correspondence: Xiao-Ping Liu; Email: 1xp22629@ sina.com; Address: The First Affiliated Hospital of Xi’an Jiaotong University, 710061, Shaanxi Province, China.
} 
been conducted in the southern and southwestern portions of China, mainly targeting injection drug users and female sex workers. ${ }^{[9,10]}$ Few studies have been conducted among migrant workers.

Tailored health education program (THEP) is one of the most useful ways of intensive or comprehensive intervention for educating the target population for their health according to their gender,age, habitat condition, education, job category, et al. So far, there are many kind of THEP which made the health education benefit from it. ${ }^{[1-15]}$ In previous studies, the diabetes patients benefit a lot from culturally tailored diabetes education and management program, ${ }^{[13-15]}$ Meanwhile, it is reported that the nurses can also get improvement in the knowledge, skills and confidence of delivering safe and competent mental health care by giving THEP, an interactive multimedia mental health education program. ${ }^{[11,12]}$ In China, many factors contribute to the vulnerability of migrant workers. ${ }^{[16]}$ In this study, we evaluated the effectiveness of an HIV/AIDS THEP in terms of increased awareness and knowledge for migrant construction workers (MCWs) in an city, China. We found that knowledge and attitudes among the MCWs significantly improved after implementation of the program, which may help to control the epidemic of HIV/AIDS in China.

\section{MeTHODS}

\subsection{Design}

This was an intervention study. THEP was used in this program. There are three stages of our study, including Education lectures, Personal consultations and distribution of education pamphlet, and Peer-education approach. The participants received the THEP for HIV/AIDS through a trained specialist, from December 2011 to May 2012. A total of 434 MCWs were randomly selected from three construction sites and invited to participate in baseline and follow-up surveys, before and after the THEP, respectively. The Ethics Review Committee of local University approved this research.

\subsection{Subjects}

The 434 MCWs enrolled in this study had been working in cities of Xi'an for more than six consecutive months and had no impairment of intelligence or cognition. Their eligibility for the study was determined by their ability to respond to the questions. All the subjects received a baseline questionnaire-survey and then underwent six months of THEP from December 2011 to May 2012. After that, the follow-up questionnaire-survey was administered.

Published by Sciedu Press

\subsection{Measures}

Surveys were conducted at baseline and after intervention by medical undergraduates. All the participants received the THEP for six months. Before and after the THEP, and after a thorough explanation of the items in the questionnaire, the participants were invited to fill in the questionnaire by themselves independent. The illiterate was helped by specially trained medical undergraduates to fill the questionnaire item by item.

\section{Ethical considerations}

The Ethics Review Committee of The First Affiliated Hospital of Xi'an Jiaotong University approved the research proposal. In addition, before data collection each relevant construction office provided approval. All participants were informed about the purposes and the methods of the investigation and intervention. They were also informed that participation in the study was voluntary, so they could refuse to participate or withdraw from the study at any time without being penalized or subjected to economic losses. Moreover, the participants were assured that their responses would be kept confidential and their identities would not be revealed in research reports or publications of the study. Lastly, the participants who agreed to participate in the investigation signed a written consent form.

\subsection{Questionnaire}

The International HIV/AIDS Questionnaire-Chinese Version (IAQ-C) with minor revisions based on the suggestions of Chinese and American experts was used in the present study. ${ }^{[16]}$ The questionnaire was pre-tested on $25 \mathrm{MCWS}$ before the survey was started and the consistency (Cronbach's $\alpha$ ) was 0.81 .

\subsection{Three stages of the study}

\section{Stage 1: Collecting basic information before the THEP}

Questionnaires were delivered to the participating MCWs at the three construction sites in December 2011 to obtain the baseline data regarding their knowledge of HIV/AIDS.

\section{Stage 2: Performing the THEP}

The THEPs given to the MCWs at the three construction sites were identical. After the THEPs were completed in May 2012, questionnaires identical to the baseline questionnaires were given to the subjects concerning their knowledge of HIV/AIDS.

\section{Stage 3: Data analysis}

Data analysis was performed using SPSS software, version 13.0. After the collection of all the valid questionnaires, the chi-squared $\left(\chi^{2}\right)$ test was used to compare the differences in survey scores before and after the intervention. 


\subsection{The process of THEP for intervention}

After the baseline measurements were obtained, an intensive and comprehensive intervention was implemented. The THEP comprised three components, each of which was performed at the three construction sites from December 2011 to May 2012.

\section{Step 1. Education lectures}

After the questionnaire-based survey at baseline, ten sessions of health lectures were delivered to all the MCWs at each of the three construction sites. The researchers covered various types of knowledge about HIV/AIDS, such as use of condoms, transmission, risk factors, prognosis, and precautions.

\section{Step 2. Personal consultations and distribution of educa-} tion pamphlet

There were three kinds of free health pamphlets offered in this study: picture-storybook, cartoon, and picture poster. Research assistants and undergraduates provided personal consultations and distributed the education pamphlets at the MCWs' dwelling place. Every MCW was provided one picture poster, and either a picture-storybook or cartoon.

\section{Step 3. Peer-education approach}

The peer-education approach was the best method for MCWs, because they had the same background and, therefore, could communicate most efficiently. Seminars were designed and implemented. Well-educated MCWs were encouraged to organize the seminar, which were attended monthly by the MCWs at the three construction sites. They discussed topics relevant to HIV/AIDS in the symposia. The organizers were financially rewarded and the attendees received gifts from the research team.

\subsection{Data quality control}

The THEP was strictly implemented by a trained researcher at each construction site. Every MCW answered the question- naire alone in a room without interference from others. The data was collected by specially trained medical undergraduates. Trained staff examined every completed questionnaire carefully. If the questionnaire was incomplete or responses were not clear, trained staff contacted the participants to fill in missing information in the questionnaire or to clarify vague answers. To confirm the validity of the obtained data, $5 \%$ of the questionnaires were randomly selected and validated by telephone query or home visits.

\section{RESULTS}

\subsection{Demographic characteristics of the participants}

Demographic characteristics, including gender, age group, education level, and family income per year, were included in the final evaluation surveys (see Table 1). Most MCWs (410 men and 24 women) were men and the age of the participants ranged from 17 to 47 years. Most (78.3\%) had less than a high school education, and most (58.8\%) reported an annual family income of Chinese renminbi (RMB) $¥ 10,000$ to (RMB) $¥ 20,000$ ( US\$1,613 to US\$3,226), although $37.1 \%$ were $>20,000$ RMB ( US\$3,226).

\subsection{Baseline of desired knowledge of HIV/AIDS in this MCWs}

Community sources of learning about HIV/AIDS for this population included: television $(72.4 \%)$, radio $(51.6 \%)$, health pamphlets $(28.8 \%)$, talking with friends $(24.2 \%)$, movies $(22.8 \%)$, lectures $(21.4 \%)$, newspapers and magazines $(21.9 \%)$, video media $(18.2 \%)$, and others $(17.1 \%)$, while the knowledge desired by the MCWS included risk factors leading to HIV/AIDS $(73.0 \%)$, prevention measures $(71.7 \%)$, therapeutic measures $(70.7 \%)$, and route of transmission $(68.9 \%)$.

Table 1. Demographics of the 434 participates

\begin{tabular}{|c|c|c|c|}
\hline & & $\mathbf{n}$ & Percentage (\%) \\
\hline \multirow{2}{*}{ Gender } & Male & 410 & 94.5 \\
\hline & Female & 24 & 5.5 \\
\hline \multirow[t]{3}{*}{ Age years } & $<20$ & 30 & 6.9 \\
\hline & $20-40$ & 365 & 84.1 \\
\hline & $>40$ & 39 & 9.0 \\
\hline \multirow{4}{*}{ Education years } & 0 & 10 & 2.3 \\
\hline & 6 & 149 & 34.3 \\
\hline & 9 & 191 & 44.0 \\
\hline & $>9$ & 84 & 19.4 \\
\hline \multirow{3}{*}{ Annual family income RMB $(\sim$ US\$) } & $<10000(<1613)$ & 18 & 4.1 \\
\hline & $10000-20000$ (1613 to 3226$)$ & 255 & 58.8 \\
\hline & $>20000(>3226)$ & 161 & 37.1 \\
\hline
\end{tabular}




\subsection{Improved knowledge of HIV/AIDS after the inter-} vention

After THEP, the MCW participants demonstrated significant improvement in HIV/AIDS knowledge. The knowledge that HIV could be transmitted by sexual intercourse, and not by mosquito bite increased from $65.4 \%$ to $100 \%$, and from $41.5 \%$ to $98.4 \%$, respectively. Knowledge of the increased ability of drug addicts and those engaging in unprotected sexual activity (e.g., no condom) to facilitate HIV transmission increased from $23 \%$ to $98.8 \%$ and from $56 \%$ to $94 \%$ (see Table 2). Attitudes of the participants toward HIV/AIDS and sexual activity changed as the result of the THEP intervention. For example, perceived HIV risk increased from 51.2\% to $97.2 \%$. The awareness of prevention of HIV transmission by using a condom and reducing the numbers of sex partners increased from $47.2 \%$ to $92.4 \%$ and $62.2 \%$ to $94.0 \%$, respectively (see Table 3 ).

Table 2. Improvement in HIV/AIDS knowledge pre- and post-intervention

\begin{tabular}{|c|c|c|c|}
\hline \multirow{2}{*}{ Survey items } & \multicolumn{2}{|c|}{ Correct answer rate $(\%) *$} & \multirow{2}{*}{$\chi^{2}$} \\
\hline & Before & After & \\
\hline 1. HIV/AIDS is an infectious disease & 78.6 & $100.0^{* *}$ & 23.96 \\
\hline 2. Sexual intercourse can transmit HIV/AIDS & 65.4 & $100.0^{* *}$ & 41.84 \\
\hline 3. An HIV vaccine is available & 38.0 & $97.2 * *$ & 80.01 \\
\hline 4. HIV can be transmitted by same-sex intercourse & 32.9 & $98.8 * *$ & 99.50 \\
\hline 5. HIV cannot be transmitted by same-sex Intercourse & 29.0 & $97.5^{* *}$ & 100.60 \\
\hline 6. HIV can be transmitted by different-sex intercourse & 24.9 & $97.0^{* *}$ & 109.21 \\
\hline 7. HIV can be transmitted from mother to fetus & 20.5 & $97.0^{* *}$ & 120.74 \\
\hline 8. HIV can be transmitted by sharing needles & 23.0 & $98.8^{* *}$ & 123.57 \\
\hline 9. Wearing condoms during sex can reduce the risk of HIV/AIDS transmission & 35.0 & $98.2^{* *}$ & 89.78 \\
\hline 10. Not reusing disposable syringescan reduce the risk of HIV/AIDS infection & 27.9 & $98.6^{* *}$ & 107.52 \\
\hline 11. Transfusion can increase the risk of HIV infection & 33.4 & $98.4^{* *}$ & 94.01 \\
\hline 12. HIV can be transmitted by sharing tableware & 34.3 & $93.3^{* *}$ & 75.36 \\
\hline 13. Coughing or sneezing can spread HIV & 38.5 & $97.9 * *$ & 81.35 \\
\hline 14. HIV cannot be transmitted by toilets, bathtubs or other public facilities & 38.0 & $98.2 * *$ & 83.41 \\
\hline 15. HIV cannot be transmitted by mosquito or insect bites & 41.5 & $98.4^{* *}$ & 77.01 \\
\hline 16. HIV cannot be transmitted by shaking hands or embracing & 42.9 & $98.4^{* *}$ & 74.27 \\
\hline
\end{tabular}

* Before intervention ( $\mathrm{n}=434)$ and after intervention $(\mathrm{n}=434)$; ** Statistically significant differences pre- and post-intervention $(P<.05)$.

Table 3. Changes in attitude and awareness regarding HIV/AIDS pre- and post-intervention

\begin{tabular}{|c|c|c|c|}
\hline \multirow{2}{*}{ Survey items } & \multicolumn{2}{|c|}{ Correct answer rate $(\%) *$} & \multirow{2}{*}{$\chi^{2}$} \\
\hline & Before & After & \\
\hline 1. The education of HIV/AIDS is necessary & 61.3 & 96.5 & $37.21 * *$ \\
\hline 2. HIV/AIDS threatens everyone & 51.2 & 97.0 & $54.75^{* *}$ \\
\hline 3. Individuals with HIV/AIDS infection should be punished & 69.1 & 96.1 & $25.36 * *$ \\
\hline 4. Prevention of HIV/AIDS is related to everyone & 51.6 & 96.8 & $53.36 * *$ \\
\hline 5. If there are friends infected HIV/AIDS, you should let everyone know that & 72.8 & 96.1 & $20.67 * *$ \\
\hline 6. Any one of us may be infected by HIV/AIDS & 35.7 & 96.1 & $81.17^{* *}$ \\
\hline 7. HIV/AIDS should be standardly medically treated & 61.8 & 96.8 & $37.31 * *$ \\
\hline 8. Disposable syringes can be exchanged or reused & 76.5 & 97.2 & $18.75^{* *}$ \\
\hline 9. No discrimination against people with HIV infection & 30.0 & 95.6 & $92.10 * *$ \\
\hline 10. Drug addiction can transmit HIV & 25.1 & 86.8 & $77.23^{* *}$ \\
\hline 11. HIV/AIDS Care should be regularly provided by the community & 61.8 & 95.4 & $33.55^{* *}$ \\
\hline 12. Disposable syringes should be used & 65.9 & 95.9 & $34.86^{* *}$ \\
\hline 13. Condoms should be used & 47.2 & 92.4 & $48.46^{* *}$ \\
\hline 14. The number of Sex partner should be limited and fixed & 62.2 & 94.0 & $29.56^{* *}$ \\
\hline 15. Drug addiction increases the likelihood of HIV infection & 58.5 & 94.5 & $36.04 * *$ \\
\hline
\end{tabular}

* Before and after THEP; ** Statistically significant differences pre- and post-intervention $(P<.05)$. 


\section{Discussion}

The effect of a THEP for enhancing knowledge of HIV/AIDS among MCWs in Western China was investigated in the present study. The intervention was conducted at three construction sites, and questionnaire-surveys were administered before and after the program to evaluate the knowledge gained by the MCW participants. We found that knowledge of the MCWs regarding HIV/AIDS was greatly improved. The results of the current study and other similar studies show that, ${ }^{[17,18]}$ given an effective mode tailored for the target audience, and by disseminating information via the appropriate media, people with relatively low education but at potentially high risk for transmission of HIV will benefit from a THEP. Different methods of health education was used depending on the target population by THEP. It is reported that the nurses can also get improvement in the knowledge, skills and confidence of delivering safe and competent mental health care by giving THEP, an interactive multimedia mental health education program. ${ }^{[11,12]}$ In China, migrant workers are at a special status due to the low level of their education, low income, poor welfare. We used the tailed health education program for migrant workers and achieved satisfactory results. The use of different teaching methods should be changed according to the background of culture of the target population. For example, the diabetes patients benefit a lot from culturally tailored diabetes education and management program and culturally sensitive patient-centred educational programme in Mexican Americans. ${ }^{[13,15]}$

In this study, we also take the cultural background into consideration when making the tailed education program. As show in the previous studies, ${ }^{[19-21]}$ after the HIV/AIDS THEP, most participants had significantly improved in their knowledge, awareness, and attitude towards HIV/AIDS prevention. We found that, before the THEP, television (72.4\%) and radio (51.6\%) were the most efficient way for these MCWS to gain information on HIV/AIDS. Print pamphlets were less accessible to these people. This may be because of their relatively low education levels. It was uncommon for this population to learn about HIV/AIDS through video media or movies, perhaps because of the cost of these sources of information and the MCWs' low income. Overall, the education program we administered on HIV/AIDS have a positive influence on attitude and awareness in this population. However, the study suffers from several limitations. Firstly, the data are cross-sectional and the results are based on self-reports. Secondly, the experiment was carried out only among MCWs, without a control group. For example, data on the percentage of condom use among urban counterparts who did not undergo the THEP were not compared.

\section{Conclusion}

MCWs in China improved their knowledge of HIV/AIDS through a THEP. THEPs designed to educate itinerant populations who have little access to other sources of information are urgently needed to help prevent the transmission of HIV in China.

\section{ACKNOWLEDGEMENTS}

We thank Professor LiuMiao, Duolao Wang, and Jos Parsons for their ideas and suggestions. We also thank Aili Lv and Mingxian Guo (Fourth Military Medical University) for their assistance. The research was supported by the Science \& Technique Foundation of Shaanxi Province (Code: 2011K1217 and 2013SF2-07) and the Clinical Research Award of the First Affiliated Hospital of Xi' an Jiaotong University, (Code: XJTU1AHCR2014-039).

\section{CONFlicts OF INTEREST Disclosure}

The authors declare that they have no competing interests.

\section{REFERENCES}

[1] WHO. Global HIV/AIDS response: epidemic update and health sector progress towards universal access. 2011. Available from: http://www.who.int/hiv/pub/progress_report2011/en/

[2] Lurie MN, Williams BG, Zuma K, et al. The impact of migration on HIV-1 transmission in South Africa: a study of migrant and nonmigrant men and their partners. Sex Transm Dis. 2003 Feb; 30(2): 149-56. PMid:12567174 http://dx.doi.org/10.1097/0 0007435-200302000-00011

[3] UNAIDS. HIV in Asia and the Pacific. New York, NY: United Nations. 2013.

[4] Tisdell C. Economic reform and openness in China: China's development policies in the last 30 years. University of Queensland. 2009.
[5] Du ML. Effect of group health education on the patients' knowledgeattitude-practice levels of serum lipids in cardiovascular department. Chin J Mod Nurs. 2010; 16(36): 4349-51.

[6] Hong Y, Stanton B, Li X, et al. Rural-to-urban migrants and the HIV epidemic in China. AIDS Behav. 2006 Jul; 10(4): 421-30. PMid:16421651 http://dx.doi.org/10.1007/s10461-005-9 039-5

[7] Rou K, Wu Z, Sullivan SG, et al. A five-city trial of a behavioural intervention to reduce sexually transmitted disease/HIV risk among sex workers in China. AIDS. 2007 Dec; 21(Suppl 8): S95-101. PMid:18172399 http://dx.doi.org/10.1097/01.ai ds.0000304703.77755.c7

[8] Chao LW, Gow J, Akintola O, et al. A Comparative Evaluation of Two Interventions for Educator Training In Hiv/Aids In South 
Africa. Int J Educ Dev Using Inf Commun Technol. 2010; 6(1): 1-14. PMid:20852677

[9] Rou K, Wu Z, Sullivan SG, et al. A five-city trial of a behavioural intervention to reduce sexually transmitted disease/HIV risk among sex workers in China. AIDS. 2007; 21(Suppl 8): S95101. PMid:18172399 http://dx.doi.org/10.1097/01.aids.0 $000304703.77755 . c 7$

[10] Wu Z, Luo W, Sullivan SG, et al. Evaluation of a needle social marketing strategy to control HIV among injecting drug users in China. Aids. 2007; 21(Suppl 8): S115-22. PMid:18172379 http: //dx.doi.org/10.1097/01.aids.0000304706.79541.ef

[11] Lamont S, Brunero S. "eSimulation" part 1: development of an interactive multimedia mental health education program for generalist nurses. Collegian. 2013; 20(4): 239-47. PMid:24596993 http://dx.doi.org/10.1016/j.colegn.2012.11.001

[12] Lamont S, Brunero S. "eSimulation". Part 2: Evaluation of an interactive multimedia mental health education program for generalist nurses. Collegian. 2014; 21(1): 3-9. http://dx.doi.org/10.10 $16 / j$.colegn.2012.11.002

[13] Mohamed H, Al-Lenjawi B, Amuna P, et al. Culturally sensitive patient-centred educational programme for self-management of type 2 diabetes: a randomized controlled trial. Prim Care Diabetes. 2013 Oct; 7(3): 199-206. PMid:23830727 http://dx.doi.org/10.10 $16 / j$. pcd. 2013.05.002

[14] Prezio EA, Cheng D, Balasubramanian BA, et al. Community Diabetes Education $(\mathrm{CoDE})$ for uninsured Mexican Americans: a randomized controlled trial of a culturally tailored diabetes education and management program led by a community health worker. Diabetes Res Clin Pract. 2013 Apr; 100(1): 19-28. PMid:23453178 http://dx.doi.org/10.1016/j.diabres.2013.01.027

[15] Rothschild SK, Martin MA, Swider SM, et al. The MexicanAmerican Trial of Community Health workers (MATCH): design and baseline characteristics of a randomized controlled trial testing a culturally tailored community diabetes self-management intervention. Contemp Clin Trials. 2012 Mar; 33(2): 369-77. PMid:22115970 http://dx.doi.org/10.1016/j.cct.2011.10.013

[16] He N, Detels R, Zhu J, et al. Characteristics and sexually transmitted diseases of male rural migrants in a metropolitan area of Eastern China. Sex Transm Dis. 2005 May; 32(5): 286 92. PMid:15849529 http://dx.doi.org/10.1097/01.olq.00 $00152219.58592 .9 \mathrm{~b}$

[17] Bland AJ, Topping A, Tobbell J. Time to unravel the conceptual confusion of authenticity and fidelity and their contribution to learning within simulation-based nurse education. A discussion paper. Nurse Educ Today. 2014 Jul; 34(7): 1112-8. PMid:24731565 http://dx.doi.org/10.1016/j.nedt.2014.03.009

[18] Happell B. Moving in circles: a brief history of reports and inquiries relating to mental health content in undergraduate nursing curricula. Nurse Educ Today. 2010 Oct; 30(7): 643-8. PMid:20138410 http://dx.doi.org/10.1016/j.nedt.2009.12.018

[19] Harvey B, Stuart J, Swan T. Evaluation of a drama-in-education programme to increase AIDS awareness in South African high schools: a randomized community intervention trial. Int J STD AIDS. 2000 Feb; 11(2): 105-11. PMid:10678478 http://dx.doi.org/10.12 58/0956462001915453

[20] Park YH, Song M, Cho BL, et al. The effects of an integrated health education and exercise program in community-dwelling older adults with hypertension: a randomized controlled trial. Patient Educ Couns. 2011 Jan; 82(1): 133-7. PMid:20434864 http://dx.doi .org/10. 1016/j.pec. 2010.04 .002

[21] Tan X, Pan J, Zhou D, et al. HIV/AIDS knowledge, attitudes and behaviors assessment of Chinese students: a questionnaire study. Int J Environ Res Public Health. 2007 Sep; 4(3): 248-53. PMid:17911665 http://dx.doi.org/10.3390/ijerph2007030009 